\title{
Genotype-related variations in proinflammatory and regulatory cytokine levels in treated and treatment-naive HCV-infected patients
}

\author{
Rasoul Baharlou ${ }^{1} \cdot$ Bizhan Romani $^{2,3} \cdot$ Seyed Jalal Kiani ${ }^{4} \cdot$ Kaveh Sadeghi $^{5} \cdot$ Enayatollah Shadmand $^{1} \cdot$ Hadi Fazel $^{6}$. \\ Farid Azizi Jalilian ${ }^{7}$ Ebrahim Kord $^{5}$. Sajad Yaghoubi ${ }^{8} \cdot$ Yousef Nikmanesh $^{5} \cdot$ Abbas Ahmadi Vasmehjani $^{1,9}$
}

Received: 23 August 2017 / Accepted: 9 November 2017 / Published online: 17 November 2017

○) Springer-Verlag GmbH Germany, part of Springer Nature 2017

\begin{abstract}
Hepatitis $\mathrm{C}$ virus (HCV) modulates immune-related inflammatory responses to induce milder reactions leading to virus persistence. In this regard, the present study aimed to investigate the link between the HCV genotypes and the proinflammatory and regulatory cytokine levels. Ninety patients with hepatitis $C$ infection (68 treatment-naive and 22 treated patients) and 76 healthy blood donors were studied. The serum levels of IFN- $\gamma$, IL-10, IL-17A, and IL-21 were measured by ELISA in the patients and healthy controls. IL-10, IL-17A, and IL-21 levels were significantly higher in HCV patients than in the healthy controls. The same cytokines were also higher in genotype 3a-infected patients compared with genotype 1a-infected patients. Interestingly, in treated patients, lower serum levels of IL-17A and IL-21 were detected in G3a-infected individuals, but not in those infected with G1a. G3a viral load displayed a significant correlation with IL-21 and IL-17A levels. In addition, G1a viral load correlated with IL-10 levels. In G3a-infected patients, a significant association was found between IL-17A serum levels and ALT. We found differences in IL-21 and IL-17A serum levels among HCV-infected patients which were genotype dependent. Since Th17-associated cytokines are associated with the progression of liver disease in HCV patients, IL-17A and IL-21 can be used as important biological markers for evaluating the immunopathogenesis of chronic hepatitis. Our results suggest that HCV G3a along with immune responses such as cytokines in HCV patients should be taken into account when interpreting clinical data and IFN-based therapeutic response.
\end{abstract}

Keywords Hepatitis C genotype $\cdot$ Inflammatory $\cdot$ Cytokines $\cdot$ Antiviral treatment

\section{Introduction}

$\mathrm{HCV}$ is an enveloped positive stranded RNA virus that has infected more than 180 million people worldwide [1]. Currently, the virus is classified into seven genotypes and 67 subtypes [2]. HCV genotypes vary substantially in their

Abbas Ahmadi Vasmehjani

ahvasmehjani@gmail.com

1 Department of Microbiology and Immunology, Jahrom University of Medical Sciences, School of Medicine, Motahari Blvd, Jahrom, Iran

2 Department of Biochemistry, University of Alberta, Edmonton, AB, Canada

3 Cellular \& Molecular Research Center (CMRC), Faculty of Medicine, Ahvaz Jundishapur University of Medical Sciences (AJUMS), Ahvaz, Iran

4 Department of Virology, School of Medicine, Iran University of Medical Sciences, Tehran, Iran geographical distribution, disease progression, and response to therapy. The most prevalent genotype is genotype 1 (subtypes $1 \mathrm{a}$ and $1 \mathrm{~b}$ in the USA and Europe, $1 \mathrm{~b}$ in Japan), followed by genotypes 3 (South Asia and Australasia), 2 (Asia Pacific, Sub-Saharan Africa), and 4 (Central Africa to the Middle East), respectively [1]. In Middle Eastern countries,

5 Virology Department, School of Public Health, Tehran University of Medical Sciences, Tehran, Iran

6 Department of Basic Medical Sciences, Neyshabur University of Medical Sciences, Neyshabur, Iran

7 Department of Microbiology, Faculty of Medicine, Hamadan University of Medical Sciences, Hamadan, Iran

8 Division of Microbiology, Department of Pathobiology, School of Public Health, Tehran University of Medical Sciences, Tehran, Iran

9 Department of Microbiology and Immunology, Jahrom University of Medical Sciences, Jahrom, Iran 
genotype 4 is the most common among Arab countries, while genotype 1 is predominant in non-Arab countries including Turkey, Iran, Cyprus, and Israel [3]. In Iran, subtypes $1 \mathrm{a}, 3 \mathrm{a}$, and $1 \mathrm{~b}$ are the most prevalent subtypes $[4,5]$. There are some controversies about correlation of HCV genotypes with any distinctive clinical outcome. A combination of host and viral factors has also been suggested to play roles in liver disease progression [6-8].

A number of studies have shown that infection with genotype $1 \mathrm{~b}$ is more frequently associated with development of chronicity, severe hepatitis, and hepatocellular carcinoma [9-11]. Moreover, genotype 3a has been linked to liver steatosis. Patients infected with genotypes 2 and 3 have higher response rates to IFN-based therapies and need lower doses of drug and duration of therapy compared with those infected with genotype 1 [12]. Although not available in all countries because of their cost, new direct acting antivirals (DAAs) are effective against all genotypes in an almost fixed duration of therapy [13].

A strong host immune response, innate and adaptive, leads to spontaneous viral clearance in $20-25 \%$ of acute $\mathrm{HCV}$ infections, while in $60-80 \%$ of infections, HCV immune evasion mechanisms result in chronic hepatitis $[14,15]$. HCV modulates the host immune responses to prevent the progress of acute disease and recovery [16]. This establishes chronic HCV infection in which a correlation has been demonstrated between production of proinflammatory cytokines (IFN- $\gamma, \mathrm{TNF}-\alpha)$ and progressive hepatic damage. On the other hand, the regulatory cytokines (IL4, IL-10) may modulate the virus-induced proinflammatory responses to induce a milder disease [17]. HCV often uses the regulatory role of IL-10 on T cells and APCs to induce $\mathrm{T}$ cell exhaustion and deactivate antiviral $\mathrm{T}$ cell immunity [18]. Th2 cytokine production is also associated with non-virological response for PegIFN/RBV therapy in chronic HCV patient [19]. Th17 cells are a subset of CD4+ $\mathrm{T}$ cells with potent proinflammatory properties by producing effector molecules including interleukin-17A (IL-17A), IL-17F, IL-21, and IL-22 [20]. They have been suggested as the major mediators of the autoimmune pathogenesis and chronic inflammatory conditions. Recent studies have demonstrated that IL-17-associated cytokines act between the inflammatory response and cell-mediated immunity in cancer and infectious diseases such as different viral infections [21-23]. Similarly, data from HIV-infected individuals have demonstrated that IL-21 is associated with viral control and slower disease progression [24]. IL-21 has also been linked to cross talk between Th17 and T regulatory cells during acute hepatitis C [25].

\section{Objectives}

To decipher the complex interactions between HCV and host immune responses, and the potential role of the inflammatory cytokines in the treatment efficacy of chronic hepatitis $\mathrm{C}$, the study of the immune cytokines in the context of infection with HCV genotypes and different phases of disease is essential. The current study therefore aimed to: (a) determine the plasma levels of INF- $\gamma$, IL-10, IL-17A, and IL-21 in HCV-infected patients compared to healthy controls; (b) determine the plasma levels of INF- $\gamma$, IL-10, IL-17A, and IL-21 based on different phases of disease and different HCV genotypes; and (c) study the link between these cytokines and clinical and laboratory findings of $\mathrm{HCV}$ viremia.

\section{Materials and methods}

\section{Study participants}

The protocol of the present study was approved by the Ethics Committee of Jahrom University of Medical Sciences and written informed consent forms were signed by all subjects. All patients were registered at the Honary Medical Clinical Centre in Jahrom, a town in the southern part of Iran, between September 2013 and February 2014. This study included 90 subjects with HCV infection in different phase of disease (acute or chronic) that were categorized into two subgroups referred to as: 67 treatment-naive and 23 treated patients. We also included 76 healthy blood donors as control. The inclusion criteria in this study were as follow: (a) adults aged more than 18 years old with the presence of anti-HCV antibodies and/or detectable serum HCV RNA, (b) serum alanine aminotransferase (ALT) higher than the normal range, and (c) in treated patients, those with sustained virologic response (SVR). Patients were excluded if they had the following concurrent diseases or conditions: (1) co-infection with HBV [hepatitis B surface antigen (HBS $\mathrm{Ag}$ ), hepatitis B core antibody (HBC Ab)], hepatitis D (hepatitis D antibody), or human immunodeficiency virus type 1 (HIV-1) (gp120 and gp41 HIV type 1 antibody and p24 antigen), (2) liver and biliary cirrhosis, (3) hepatic failure, (4) renal function impairment, (5) autoimmune hepatitis, (6) Wilson disease, (7) liver transplantation, (8) uncontrolled diabetes mellitus, or (9) the presence of hepatocellular carcinoma or other malignancy. Recent HCV infections such as acute or early chronic infections were defined by an initial positive anti-HCV antibody test within 6 months of enrollment. Acute clinical infection was defined by symptomatic seroconversion illness or abnormal ALT levels ranging from 2- to 20-fold higher than the upper limit of normal level at 
the time of HCV detection [26-28]. Chronic HCV infection was defined as detectable HCV RNA at 6 months after the time of infection.

\section{Combination pegylated-interferon alpha (PEG-IFNa) and ribavirin (RBV)}

All the participants subcutaneously received peg-interferon $\alpha-2 \mathrm{a}(180 \mu \mathrm{g} /$ week $)$ plus weight-based ribavirin (800-1200 mg per day). A 24-week regimen was administered to patients with HCV-3 or HCV-1 with rapid virologic response (RVR), which was defined as negative $\mathrm{HCV}$ RNA after 4 weeks of treatment. For those with HCV-1 who failed to achieve RVR, the treatment course was extended to 48 weeks. Sustained virologic response (SVR), which was achieved for all treated patients, was defined as clearance of the serum HCV RNA at the end of the therapy and lasting for more than 24 weeks after the cessation of therapy [29].

\section{HCV RNA loading and genotyping:}

Six milliliters of whole blood sample was collected from each individual and all plasma samples were isolated from each $0.5 \mathrm{M}$ EDTA-treated blood samples by centrifuging at $3000 \mathrm{rpm}$, for $15 \mathrm{~min}$, and then preserved at $-80{ }^{\circ} \mathrm{C}$. According to the manufacturer's instructions, RNA was extracted from $100 \mu \mathrm{L}$ of plasma, using the AccuPrep Viral RNA Extraction Kit (Bioneer, South Korea). HCV genotyping was performed using type-specific primers according to the protocol described previously [30]. Briefly, genotyping was performed using genotype-specific primers $(1 \mathrm{a}, 1 \mathrm{~b}$, 3 ) based on the amplified 5'-untranslated region (5'-UTR) of the HCV genome. Each type-specific HCV primer was fluorescently labeled on the 5 '-end. The primer sequences, the dye labels, and the sizes of the expected products were different as described previously [5]. Reverse transcription (RT)-PCR was performed with primers KY80 (5'-GCA GAA AGC GTC TAG CCA TGG CGT-3') and KY78 (5'CTC GCA AGC ACC CTA TCA GGC AGT-3') to amplify a 244 bp fragment of the HCV 5'-untranslated region (5'UTR). We used different samples with specific HCV genotypes as positive controls. Moreover, genotyping was confirmed by sequencing as described elsewhere [5].

Hepatitis C RNA levels were assessed by quantitative reverse transcription-polymerase chain reaction (qRT-PCR) according to Roche Cobas TaqMan HCV assay (Roche Molecular Systems, Pleasanton, CA) [31]. Briefly, a total volume of $20 \mu 1$ reaction mixture consisted of $5 \mu \mathrm{l}$ TaqMan buffer, $500 \mathrm{nM}$ of each primer from the HCV 5-noncoding region (5'-GAGTGTCGTGCAGCC TCCA-3' (and (5'-CACTCGCAAGCACCCTATCA-3'), $200 \mathrm{nM}$ of fluorogenic probe [5-(6-carboxyfluorescein) CCCGCAAGACTGCTAGCCGAGTAGTGTTGG (6-carboxytetramethylrhodamine)-3], $200 \mathrm{M}$ of each deoxynucleotide triphosphate (dNTP), $5 \mathrm{U}$ of DNA polymerase, and $5 \mu \mathrm{L}$ template RNA. Probe signals were detected using real-time PCR (7500 Real-Time PCR system; Applied BioSystems, USA). The lower limit of detection for this test is $100 \mathrm{IU} / \mathrm{mL}$.

\section{Measurement of plasma cytokines}

To explore the interactions between HCV and host immune responses, serum levels of two proinflammatory and regulatory cytokines, as well as two cytokines produced mainly by Th17 cells were investigated. Briefly, serum levels of IFN$\gamma$, IL-10, IL-17A, and IL-21 cytokines were measured in all patients (treated and treatment-naive) and control group, using commercial ELISA kits (eBioscience, San Diego, $\mathrm{CA}$ ), according to the manufacturer's protocols. The sensitivity of the detection for INF- $\gamma$, IL-10, IL-17A, and IL-21 was $4,1,4$, and $8 \mathrm{pg} / \mathrm{mL}$, respectively. The results were presented as $\mathrm{pg} / \mathrm{mL}$.

\section{Clinical chemistry}

ALT and AST activity was determined by the colorimetric method using Olympus AU400 auto-analyser machine (Mishima Olympus Co. Ltd., Shizuoka-ken, Japan) in the plasma samples. Reference values for ALT and AST were set at $(<57$ and $\geq 57)$ and $(<41$ and $\geq 41) \mathrm{U} / \mathrm{L}$, respectively, and data were reported in international units (IU)/L.

\section{Statistical analysis}

GraphPad Prism version 5.0 (GraphPad Software, San Diego, CA, USA) was used to analyze the data using nonparametric Kruskal-wallis and Mann-Whitney tests. Proportion analysis was performed using $\chi^{2}$ test, and the correlation between two categorical groups was analyzed using the Spearman's test. A $p$ value of less than 0.05 was considered to be statistically significant.

\section{Results}

\section{Participant characteristics}

The clinical and laboratory parameters of patients and controls are summarized in Table 1. Of 90 patients, 57 (63.3\%) were male and $33(46.7 \%)$ were female. 76 healthy controls with normal ALT levels were also included. The healthy controls included 43 (56.6\%) men and 33 (43.4\%) women who had no medical history of any liver disease. The frequency of G3a and G1a in chronic HCV patients was $65.6 \%$ (59/90) and $34.4 \%$ (31/90), respectively. Our results showed 
Table 1 Clinical and laboratory parameters in hepatitis $\mathrm{C}$ patients and control group

\begin{tabular}{lllll}
\hline Variables $^{\mathrm{a}}$ & Treatment-naive $(n=67)$ & Treated $(n=23)$ & Healthy control $(n=76)$ & $p$ \\
\hline Sex & & & & 0.12 \\
Male & $48(71.6 \%)$ & $9(39.1 \%)$ & 43 & \\
Female & $19(28.4 \%)$ & $14(60.9 \%)$ & 33 & 0.001 \\
ALT (IU/L) & $60.32 \pm 2.69$ & $43.27 \pm 3.51$ & $30.16 \pm 0.87$ & 0.076 \\
AST (IU/L) & $37.80 \pm 1.19$ & $37.54 \pm 3.17$ & $32.48 \pm 1.50$ & - \\
Viral titer (IU/mL) & $1.4837 \times 10^{6} \pm 9.0 \times 10^{4}$ & 0 & - & 0.11 \\
Phase of disease & & & - & \\
Acute & $12(17.9 \%)$ & $1(4.3 \%)$ & - & 0.32 \\
Chronic & $55(82.1 \%)$ & $22(95.7 \%)$ & & \\
Genotypes & & & - & \\
1a & $25(37.3 \%)$ & $6(26.1 \%)$ & - & \\
3a & $42(62.7 \%)$ & $17(73.9 \%)$ & - & \\
\hline
\end{tabular}

${ }^{a}$ Data are expressed as mean \pm SD for quantitative measures and both number and percentage for categorized data

${ }^{\mathrm{b}}$ Comparison using $\chi^{2}$ test that ALT and AST levels in the HCV patients (treatmentnaive and treated) groups were significantly higher than those in the control group (Table 1).

\section{Serum IFN- - , IL-10, IL-21, and IL-17A levels}

Although there was no significant difference in IFN- $\gamma$ serum levels (Fig. 1d), a 3.5-fold higher IL-10 level was found in HCV-infected patients (Fig. 1a). Moreover, as shown in Fig. 1b, c, higher levels of IL-17A and IL-21 in HCVinfected patients were observed compared with healthy controls ( three-fold and two-fold, respectively). On the other hand, treated patients showed significantly lower levels of IL-17A and IL-21. Lower IL-10 serum level was also found significant in this group (Fig. 1a).

\section{HCV genotypes and serum levels of IFN- $-\mathrm{y}$ IL-10, IL-21, and IL-17A}

The serum levels of IFN- $\gamma$, IL-10, IL-17A, and IL-21 cytokines were determined in treated and treatment-naive patients with respect to the HCV genotypes. As shown in Fig. 2d, no significant difference was observed in IFN- $\gamma$ levels. Although significantly higher levels of IL-10 were found in G3a-infected patients, the difference observed in treated and treatment-naive patients was non-significant. However, in treated patients, there was a significantly lower IL-10 levels in G1a-infected patients (Fig. 2a). Interestingly, higher levels of both IL-17A and IL-21 cytokines were observed in G3a-infected patients. The same pattern was also observed in G3a-treatment-naive patients in comparison to G1a-treatment-naive patients. Significantly lower 17A and IL-21 levels were also observed in G3a-treated patients compared to G3a-treatment-naive patients (Fig. 2b, c).

\section{Clinicopathological parameters and serum levels of IFN- $\gamma$, IL-10, IL-21, and IL-17A}

Serum IFN- $\gamma$, IL-10, IL-21, and IL-17A levels with respect to different clinicopathological parameters of the patients have been summarized in Table 2. Although similar levels of these cytokines were found in the serum of chronic and acute HCV infections, IFN- $\gamma$ and IL-21 levels in chronic HCV infections were lower than those in acute HCV infections.

An analysis was performed with respect to ALT and AST levels and viral load with IFN- $\gamma$, IL-10, IL-21, and IL-17A serum levels and a correlation was found between IL-10 and IL-21 levels and viral load (Table 3). Further analysis was performed with respect to HCV G1a and G3a and significant correlations were found between increasing levels of IL-21 (Fig. 3e) and IL-17A (Fig. 3c) with G3a viral load as well as increasing levels of IL-10 with G1a viral load (Fig. 3a). In addition, in G3a-infected patients, a significant association was found between the increase in IL-17A serum levels and the increase in serum ALT (Fig. 3b).

\section{Discussion}

It is known that several host and viral factors determine the outcome of HCV infection. The genotype of the virus, viral load, and profile of the host cytokines and chemokines have been suggested to play roles in this regard [32]. Proinflammatory and regulatory cytokines have a prominent role in the pathogenesis of HCV infection [16, 33]. However, the exact role of these cytokines is not fully understood in hepatitis $\mathrm{C}$ immunopathogenesis. In this study, we investigated the immune responses of $\mathrm{HCV}$-infected patients by determining 

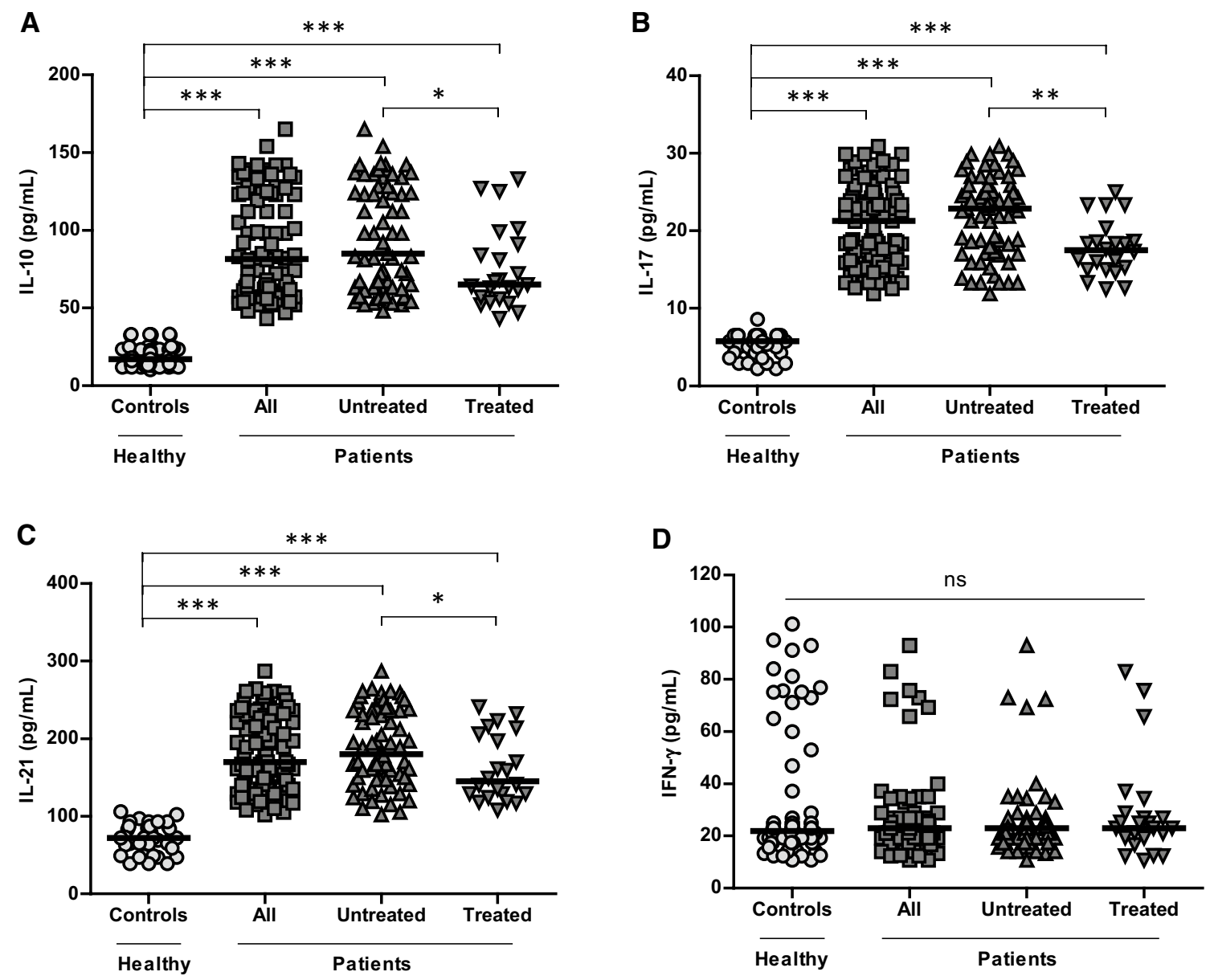

Fig. 1 Serum levels of IL-10, IL-17, IL-21, and IFN- $\gamma$ in the peripheral blood of HCV-infected patients and healthy controls. a Distribution of IL-10 levels; b distribution of IL-17 levels; $\mathbf{c}$ distribution of IL-21 levels; and d distribution of IFN- $\gamma$ levels, in HCV-infected

serum levels of several proinflammatory and regulatory cytokines including IFN- $\gamma$, IL-10, IL-21, and IL-17A.

Although the serum level of IFN- $\gamma$ did not change in the patients, our study revealed significantly higher serum levels of IL-17, IL-21, and IL-10 in HCV-infected patients than the control group. Since increased proportions of Th17 cells both in circulation and liver correlate with the severity of liver inflammation and damage, Th17-associated cytokines may play roles in the progression of liver disease [22, 34].

After infection, the plasma level of IL-17, which is produced by Th17, Tc17, NK, monocyte, and $\gamma \delta \mathrm{T}$ cells, is elevated. This proinflammatory cytokine recruits monocytes and neutrophils to the site of infection [35], increases T cell infiltration [36], and induces IL-6 production to activate immune responses [37]. On the contrary, some evidence suggests that IL-17A may cause upregulation of antiapoptotic molecules in liver cells, assisting in hepatic viral persistence [38]. Chang et al. [22] showed that IL-17A levels increased in chronic $\mathrm{HCV}$ patients in comparison to healthy controls.

patients compared to controls. Horizontal lines represent the median of cytokine levels in each subgroup. ${ }^{*} p<0.05, * * p<0.01$, $* * * p<0.0001$

However, Foster et al. [34] found no difference between chronic HCV patients and healthy controls. Our data show higher IL-17A levels in chronic HCV patients, indicating its potential role in the development of viral persistency.

IL-21, which is produced by NKT, Th17, Tfh, Th9, and Tc cells, can increase proliferation of CD4+ T cells and differentiation into Th17 cells (together with IL-6). It also stimulates proliferation and function of $\mathrm{CD} 8+\mathrm{T}$ cells and NK cells. Moreover, IL-21 has various effects on B-cells including proliferation, differentiation, or apoptosis based on the stimulation and cell type [39]. Elevated serum levels of IL-21 have been demonstrated in HBV and HCV infections [40-42]. Our study shows higher levels of both IL-17 and IL-21, which can be interpreted as interplay between IL-21-producing CD4+ T cells and Th17 cells. In the presence of IL-6, IL-21 triggers the differentiation of Th17 cells, which produces IL-21 as one of its cytokines and this autocrine pathway may result in elevated levels of both cytokines. 

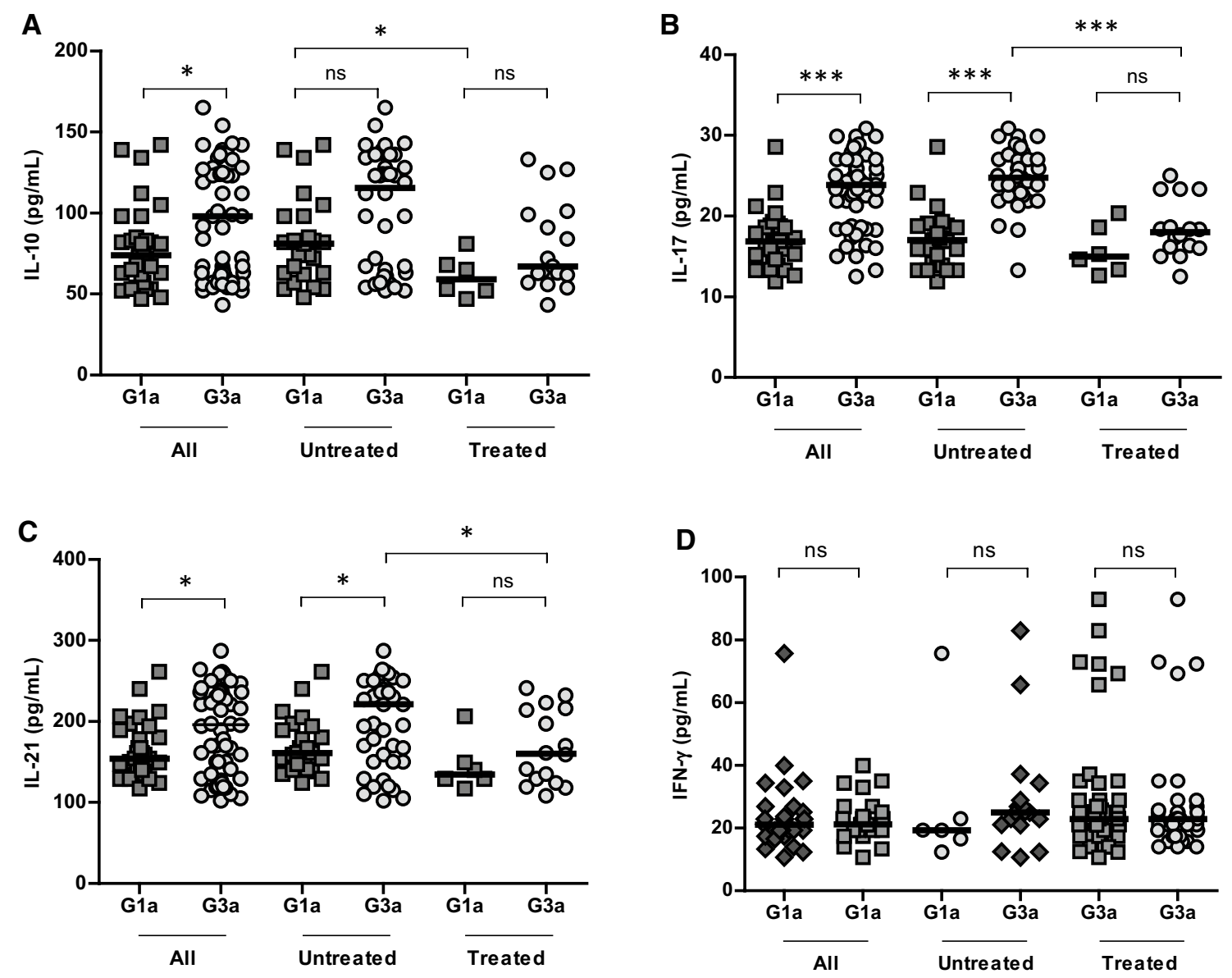

Fig. 2 Serum levels of IL-10, IL-17, IL-21, and IFN- $\gamma$ in treated and treatment-naive patients with respect to HCV genotypes. a Distribution of IL-10 levels by HCV genotypes; $\mathbf{b}$ distribution of IL-17 levels by HCV genotypes; $\mathbf{c}$ distribution of IL-21 levels by HCV genotypes;

Elevated serum levels of IL-10 are associated with the persistence in HCV and HIV infections [43, 44]. Increased IL-10 production by dendritic cells (DCs), CD4+ T cells, and NK cells induces loss of $T$ cell responses ( $T$ cell exhaustion). This also affects the inflammatory balance necessary to mount effective $\mathrm{T}$ cell responses and promotes the development of persistent/chronic infections [18]. Interestingly, our study demonstrated that higher viral loads were significantly associated with higher levels of IL-10 and IL-21. Although the increase in IL-10 levels has been reported in the development of persistent $\mathrm{HCV}$ infection, it seems that IL-21-producing CD4+ T cells try to provide more IL-21 which in combination with other yet unidentified factors help to maintain the CD8+ T cell effector activity. This is required to acutely clear the infection and prevent the induction of IL-10-associated exhaustion in CD8+ T cells [23].

Successful treatment, which is defined as sustained virologic response (SVR), results in undetectable HCV RNA 12 weeks after completion of therapy and could lead to and $\mathbf{d}$ distribution of IFN- $\gamma$ levels by HCV genotypes in all patients as well as in treated and treatment-naive patients. Horizontal lines represent the median of cytokine levels in each subgroup. ${ }^{*} p<0.05$, $* * p<0.01, * * * p<0.0001$

substantial changes in the liver and blood cytokine microenvironment. The results of the present study showed significantly lower IL-17, IL-21, and IL-10 serum levels in treated patients, while IFN- $\gamma$ level was not altered. This is consistent with the results obtained by Jimenez-Sousa et al., which showed that combined treatment with pegylated interferon alpha and ribavirin down-modulates the secretion of key proinflammatory and pro-fibrotic mediators [45]. This could be due to the immunomodulatory properties of these drugs. However, some inconsistency, particularly in the reduced levels of IFN- $\gamma$ after therapy, has been reported by Fathy et al. in chronic HCV infection [46]. The differences between these studies may come from differences in sample size, liver fibrosis stage, genetic markers such as IL-28B single nucleotides polymorphisms (SNPs) [47, 48], and host immunity [49] that could interfere with the therapeutic response. As mentioned above, we found higher serum levels of IL-21 in treatment-naive patients than treated patients which is also consistent with Hsu et al. [50]. Elevated IL-21 levels 
Table 2 Serum levels of IL-10, IL-17, IL-21, and IFN- $\gamma$ based on the clinicopathological parameters of HCV patients

\begin{tabular}{|c|c|c|c|c|c|c|c|c|}
\hline & \multicolumn{2}{|l|}{ Gender } & \multicolumn{2}{|c|}{ Phase of disease } & \multicolumn{2}{|l|}{$\mathrm{AST}^{\mathrm{b}}$} & \multicolumn{2}{|l|}{$\mathrm{ALT}^{\mathrm{b}}$} \\
\hline & Male & Female & Acute & Chronic & $<41$ & $\geq 41$ & $<57$ & $\geq 57$ \\
\hline \multicolumn{9}{|l|}{ IL-10 } \\
\hline Mean \pm SD & $93.80 \pm 33.06$ & $82.54 \pm 33.04$ & $98.0 \pm 34.66$ & $88.27 \pm 33.11$ & $89.29 \pm 30.92$ & $89.90 \pm 34.97$ & $83.16 \pm 31.34$ & $98.19 \pm 34.29$ \\
\hline Median & 92.0 & 67.0 & 98.0 & 81.0 & 83.50 & 77.50 & 72.0 & 101.0 \\
\hline$p$ & NS & & NS & & NS & & NS & \\
\hline \multicolumn{9}{|l|}{ IL-17 } \\
\hline Mean \pm SD & $21.20 \pm 0.69$ & $20.54 \pm 4.93$ & $22.49 \pm 5.19$ & $20.70 \pm 5.11$ & $22.07 \pm 4.66$ & $20.28 \pm 5.32$ & $19.56 \pm 4.73$ & $22.79 \pm 5.11$ \\
\hline Median & 21.90 & 20.36 & 23.29 & 20.36 & 23.36 & 19.07 & 18.66 & 23.90 \\
\hline$p$ & NS & & NS & & NS & & 0.003 & \\
\hline \multicolumn{9}{|l|}{$\mathrm{IL}-21^{\mathrm{a}}$} \\
\hline Mean \pm SD & $78.09 \pm 36.98$ & $71.29 \pm 39.35$ & $83.51 \pm 46.18$ & $74.26 \pm 36.37$ & $76.86 \pm 42.76$ & $74.83 \pm 34.82$ & $79.92 \pm 39.78$ & $71.25 \pm 35.04$ \\
\hline Median & 69.0 & 56.0 & 59.0 & 63.0 & 60.99 & 63.50 & 67.0 & 57.0 \\
\hline$p$ & NS & & 0.02 & & NS & & NS & \\
\hline \multicolumn{9}{|l|}{ IFN- $\gamma^{\mathrm{a}}$} \\
\hline Mean \pm SD & $24.99 \pm 13.84$ & $28.82 \pm 18.70$ & $35.50 \pm 26.02$ & $24.86 \pm 13.0$ & $25.86 \pm 13.73$ & $26.72 \pm 17.05$ & $26.16 \pm 17.70$ & $26.70 \pm 13.44$ \\
\hline Median & 21.17 & 22.99 & 22.99 & 22.99 & 22.99 & 22.34 & 21.70 & 22.99 \\
\hline$p$ & NS & & 0.001 & & NS & & NS & \\
\hline
\end{tabular}

${ }^{\mathrm{a}} \mathrm{pg} / \mathrm{mL},{ }^{\mathrm{b}} \mathrm{IU} / \mathrm{mL}$, the presented data were analyzed with the nonparametric two-tailed Mann-Whitney test

Table 3 Correlations between serum parameters and viral load with IL-10, IL-17, IL-21, and IFN- $\gamma$ in HCV patients

\begin{tabular}{lllll}
\hline Variables & IL-10 & IL-17 & IL-21 & IFN- $\gamma$ \\
\hline AST & & & & \\
$r$ & -0.19 & 0.16 & 0.11 & 0.05 \\
$p$ & $\mathrm{NS}$ & $\mathrm{NS}$ & $\mathrm{NS}$ & $\mathrm{NS}$ \\
ALT & & & & \\
$r$ & 0.17 & 0.32 & -0.04 & 0.08 \\
$p$ & $\mathrm{~N} . \mathrm{S}$ & 0.002 & $\mathrm{NS}$ & $\mathrm{NS}$ \\
Viral load & & & & \\
$r$ & 0.22 & 0.18 & 0.22 & -0.93 \\
$p$ & 0.03 & $\mathrm{NS}$ & 0.03 & $\mathrm{NS}$ \\
\hline
\end{tabular}

The correlation was evaluated using Spearman's rank correlation coefficient

may be induced by the CD4+ T cell-mediated response to $\mathrm{HCV}$ infection and a higher serum IL-21 level may represent a more severe infection [23]. However, more studies are needed to elucidate the detailed mechanisms involved in this increase.

It has been shown that the progression of chronic $\mathrm{HCV}$ is highly variable among infected individuals as a result of several factors including, but not restricted to, host immunogenetic factors and viral genotype. Consistent with SamimiRad et al. [4], the most prevalent subtypes in our study were 1a and 3a. However, higher prevalence of subtype $3 \mathrm{a}$ compared to 1a may be associated with the increase in intravenous drug abuse and needle sharing. Our study, for the first time, revealed higher levels of IL-10, IL-21, and IL-17 in patients infected with G3a in comparison with those infected with G1a. Similarly to our findings, elevated levels of IL-17 have also been reported for genotype 4-infected individuals [51]. Although we found that IFN-based therapy resulted in lower IL-10 levels, both in G1a- and 3a-infected individuals, lower IL-17 and IL-21 levels were only observed in patients infected with G3a, and not with G1a.This might be due to the induction of higher levels of IL-17 and IL-21 by G3a in infected individuals in comparison with G1a. This is supported by the association found between G3a viral load and higher levels of both IL-17 and IL-21 (Fig. 3). Subsequently, the correlation found between higher serum levels of IL-17 and ALT may support the role of G3a in induction of higher levels of ALT, which is associated with more frequent progress of liver disease [52]. The cytokine profile of infection with different $\mathrm{HCV}$ genotypes has not been sufficiently addressed and more studies are needed to elucidate the role of viral genotypes in immune response.

The present study provides strong evidence for correlation between the serum concentrations of IL-17 and ALT. It has been shown that elevated levels of IL-17 are associated with the extent of liver damage [53,54]. IL-17 activates a variety of immune cells to release inflammatory mediators, leading to repeated inflammation of the liver and deterioration of liver damage. Although one study showed no correlation between serum IL-17 and ALT, it should be noted that the latter can be easily affected by drugs which decrease its level [35]. Patients with chronic HBV infection showed a positive correlation between the frequency of circulating 

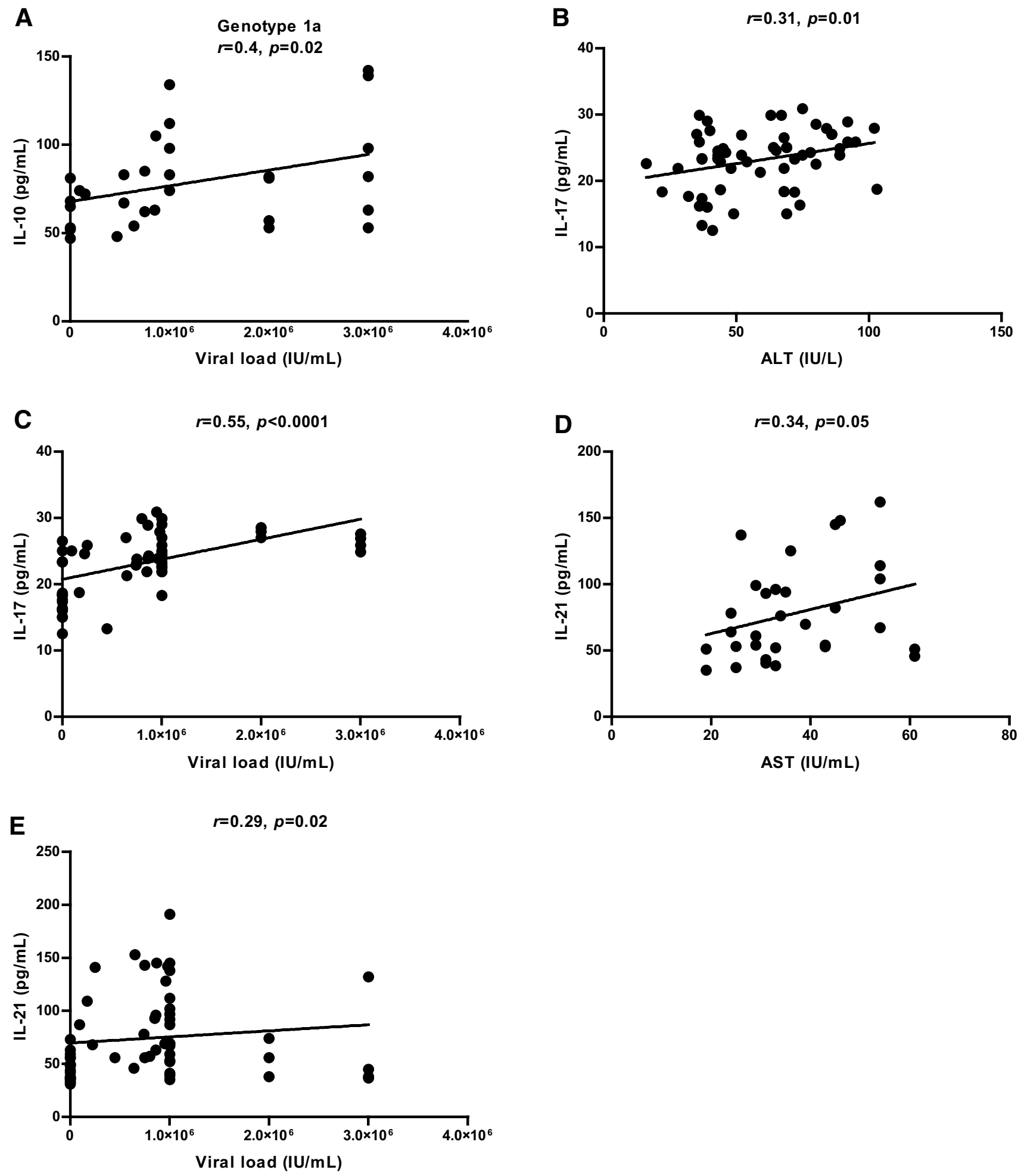

Fig. 3 Association of AST, ALT, and HCV RNA levels with IL-10, IL-17, and IL-21 levels in patients with genotypes 1a and 3a. a Distribution of IL-10 levels by G1a viral load; $\mathbf{b}$ distribution of IL-17 levels by G3a viral load; c distribution of IL-21 levels by G3a viral load;

d distribution of IL-17 levels by ALT levels in G3a-infected patients; e distribution of IL-21 levels by AST levels in G1a-infected patients. Oblique lines represent the best fit linear line 
Th17 cells and ALT levels [21], and increased serum IL-17 levels in chronic HBV infection were also described [55]. Since both HBV and HCV induce immune-mediated liver damage, similar pathways underlying Th17 cells may be involved to induce inflammation, such as monocyte activation and neutrophil recruitment.

Introduction of the new direct acting antiviral (DAA) therapies for $\mathrm{HCV}$ infection has opened a new era with higher SVR rates in all genotypes and lower side effects. Although not available in all countries because of their cost, administration of DAAs for HCV-infected patients is increasing; however, the potential interactions between viral and host factors have not been sufficiently addressed. Considering the IFN-free nature of these treatments and HCV genotype-based variations in immune responses, the effect of treatment on the proinflammatory and regulatory cytokine patterns is not known yet and remains to be elucidated by future studies.

In conclusion, we demonstrated that $\mathrm{HCV}$-infected patients displayed higher serum levels of IL-10, IL-17, and IL-21 than healthy controls. The same pattern was observed in G3a-infected patients in comparison to those infected with G1a. Interestingly, in treated patients, significantly lower levels of IL-17 and IL-21 were found only in patients infected with G3a.

Acknowledgements The authors thank Mohammad Reza Shokouh (Department of microbiology and immunology at University of Jahrom) for the excellent technical assistance. We thank the anonymous patients and blood donors who provided the samples for our study.

\section{References}

1. Thrift AP, El-Serag HB, Kanwal F (2016) Global epidemiology and burden of HCV infection and HCV-related disease. Nat Rev Gastroenterol Hepatol 14(2):122-132

2. Smith DB, Bukh J, Kuiken C, Muerhoff AS, Rice CM, Stapleton JT, Simmonds P (2014) Expanded classification of hepatitis $\mathrm{C}$ virus into 7 genotypes and 67 subtypes: updated criteria and genotype assignment web resource. Hepatol 59(1):318-327

3. Ghaderi-Zefrehi H, Gholami-Fesharaki M, Sharafi H, Sadeghi F, Alavian SM (2016) The distribution of hepatitis C virus genotypes in Middle Eastern Countries: a systematic review and meta-analysis. Hepat Mon 16(9):e40357

4. Samimi-Rad K, Nategh R, Malekzadeh R, Norder H, Magnius L (2004) Molecular epidemiology of hepatitis C virus in Iran as reflected by phylogenetic analysis of the NS5B region. J Med virol 74(2):246-252

5. Ashrafi Hafez A, Baharlou R, Mousavi Nasab SD, Ahmadi Vasmehjani A, Shayestehpour M, Joharinia N, Ahmadi NA (2014) Molecular epidemiology of different hepatitis $\mathrm{C}$ genotypes in serum and peripheral blood mononuclear cells in jahrom city of Iran. Hepat Mon 14(5):e16391

6. Oliveira KG, Malta FM, Nastri AC, Widman A, Faria PL, Santana RA, Alves VA, Carrilho FJ, Pinho JR (2016) Increased hepatic expression of miRNA-122 in patients infected with HCV genotype 3. Med Microbiol Immun 205(2):111-117
7. Alborzi A, Hashempour T, Moayedi J, Musavi Z, Pouladfar G, Merat S (2017) Role of serum level and genetic variation of IL-28B in interferon responsiveness and advanced liver disease in chronic hepatitis $\mathrm{C}$ patients. Med Microbiol Immun 206(2):165-174

8. Zein NN (2000) Clinical significance of hepatitis C virus genotypes. Clin Microbiol Rev 13(2):223-235

9. Zein NN, Rakela J, Krawitt EL, Reddy KR, Tominaga T, Persing DH (1996) Hepatitis C virus genotypes in the United States: epidemiology, pathogenicity, and response to interferon therapy. Ann Intern Med 125(8):634-639

10. Pozzato G, Moretti M, Crocé LS, Sasso F, Tiribelli C, Crovatto M, Santini G, Kaneko S, Unoura M, Kobayashi K (1995) Interferon therapy in chronic hepatitis $\mathrm{C}$ virus: evidence of different outcome with respect to different viral strains. J Medi Virol 45(4):445-450

11. Amoroso P, Rapicetta M, Tosti ME, Mele A, Spada E, Buonocore S, Lettieri G, Pierri P, Chionne P, Ciccaglione AR (1998) Correlation between virus genotype and chronicity rate in acute hepatitis C. J hepatol 28(6):939-944

12. Hnatyszyn HJ (2005) Chronic hepatitis $C$ and genotyping: the clinical significance of determining HCV genotypes. Antivir Ther 10(1):1-11

13. Falade-Nwulia O, Suarez-Cuervo C, Nelson DR, Fried MW, Segal JB, Sulkowski MS (2017) Oral direct-acting agent therapy for hepatitis $\mathrm{C}$ virus infectiona systematic revieworal direct-acting agent therapy for HCV infection. Ann Intern Med 166(9):637-648

14. Antonelli AFC, Galeazzi M, Giannitti C et al (2008) HCV infection: pathogenesis, clinical manifestations, and therapy. Clin Exp Rheumatol 26(1 Suppl 48):39-47

15. Fujii L, Orozco JFG (2008) Virus persistence in hepatitis C: lifelong infection despite therapy? Med Univ 10(41):216-224

16. Park S-H, Rehermann B (2014) Immune responses to HCV and other hepatitis viruses. Immunity 40(1):13-24

17. Hofmann SR, Ettinger R, Zhou Y-J, Gadina M, Lipsky P, Siegel R, Candotti F, O'shea JJ (2002) Cytokines and their role in lymphoid development, differentiation and homeostasis. Curr Opin Allergy Clin Immunol 2(6):495-506

18. Rojas JM, Avia M, Martín V, Sevilla N (2017) IL-10: a multifunctional cytokine in viral infections. J Immunol Res 2017 2017:6104054

19. Yoneda S, Umemura T, Katsuyama Y, Kamijo A, Joshita S, Komatsu M, Ichijo T, Matsumoto A, Yoshizawa K, Ota M (2011) Association of serum cytokine levels with treatment response to pegylated interferon and ribavirin therapy in genotype 1 chronic hepatitis C patients. J Infect Dis 203(8):1087-1095

20. Ouyang W, Kolls JK, Zheng Y (2008) The biological functions of T helper 17 cell effector cytokines in inflammation. Immunity 28(4):454-467

21. Zhang JY, Zhang Z, Lin F, Zou ZS, Xu RN, Jin L, Fu JL, Shi F, Shi M, Wang HF (2010) Interleukin-17-producing CD4+T cells increase with severity of liver damage in patients with chronic hepatitis B. Hepatol 51(1):81-91

22. Chang Q, Wang YK, Zhao Q, Wang CZ, Hu YZ, Wu BY (2012) Th17 cells are increased with severity of liver inflammation in patients with chronic hepatitis C. J Gastroenterol Hepatol 27(2):273-278

23. Elsaesser H, Sauer K, Brooks DG (2009) IL-21 is required to control chronic viral infection. Science 324(5934):1569-1572

24. Yue FY, Lo C, Sakhdari A, Lee EY, Kovacs CM, Benko E, Liu J, Song H, Jones RB, Sheth P (2010) HIV-specific IL-21 producing $\mathrm{CD} 4+\mathrm{T}$ cells are induced in acute and chronic progressive HIV infection and are associated with relative viral control. J Immunol 185(1):498-506

25. Kared H, Fabre T, Bedard N, Bruneau J, Shoukry NH (2013) Galectin-9 and IL-21 mediate cross-regulation between Th17 and Treg cells during acute hepatitis C. PLoS Pathog 9(6):e1003422 
26. Hajarizadeh B, Lamoury FM, Feld JJ, Amin J, Keoshkerian E, Matthews GV, Hellard M, Dore GJ, Lloyd AR, Grebely J (2016) Alanine aminotransferase, HCV RNA levels and pro-inflammatory and pro-fibrogenic cytokines/chemokines during acute hepatitis $\mathrm{C}$ virus infection. Virol J 13(1):32

27. McGovern BH, Birch CE, Bowen MJ, Reyor LL, Nagami EH, Chung RT, Kim AY (2009) Improving the diagnosis of acute hepatitis $\mathrm{C}$ virus infection with expanded viral load criteria. Clin Infect Dis 49(7):1051-1060

28. Micallef J, Kaldor J, Dore G (2006) Spontaneous viral clearance following acute hepatitis $\mathrm{C}$ infection: a systematic review of longitudinal studies. J Viral Hepa 13(1):34-41

29. Ghany MG, Strader DB, Thomas DL, Seeff LB (2009) Diagnosis, management, and treatment of hepatitis $\mathrm{C}$ : an update. Hepatol 49(4):1335-1374

30. Antonishyn NA, Ast VM, McDonald RR, Chaudhary RK, Lin L, Andonov AP, Horsman GB (2005) Rapid genotyping of hepatitis $\mathrm{C}$ virus by primer-specific extension analysis. J Clin Microbiol 43(10):5158-5163

31. Suzuki T, Omata K, Satoh T, Miyasaka T, Arai C, Maeda M, Matsuno T, Miyamura T (2005) Quantitative detection of hepatitis $\mathrm{C}$ virus (HCV) RNA in saliva and gingival crevicular fluid of HCV-infected patients. J Clin Microbiol 43(9):4413-4417

32. Yan Z, Wang Y (2017) Viral and host factors associated with outcomes of hepatitis $\mathrm{C}$ virus infection. Mol Med Rep 15(5):2909-2924

33. Shin E-C, Sung PS, Park S-H (2016) Immune responses and immunopathology in acute and chronic viral hepatitis. Nat Rev Immunol 16(8):509-523

34. Foster RG, Golden-Mason L, Rutebemberwa A, Rosen HR (2012) Interleukin (IL)-17/IL-22-producing T cells enriched within the liver of patients with chronic hepatitis $\mathrm{C}$ viral (HCV) infection. Dig Dis Sci 57(2):381-389

35. Woltman AM, De Haij S, Boonstra JG, Gobin SJ, Daha MR, Van Kooten C (2000) Interleukin-17 and CD40-ligand synergistically enhance cytokine and chemokine production by renal epithelial cells. J Am Soc Nephrol 11(11):2044-2055

36. Albanesi C, Cavani A, Girolomoni G (1999) IL-17 is produced by nickel-specific T lymphocytes and regulates ICAM-1 expression and chemokine production in human keratinocytes: synergistic or antagonist effects with IFN- $\gamma$ and TNF- $\alpha$. J Immunol 162(1):494-502

37. Ogura H, Murakami M, Okuyama Y, Tsuruoka M, Kitabayashi C, Kanamoto M, Nishihara M, Iwakura Y, Hirano T (2008) Interleukin-17 promotes autoimmunity by triggering a positive-feedback loop via interleukin-6 induction. Immunity 29(4):628-636

38. Bălănescu P, Lădaru A, Voiosu T, Nicolau A, Ene M, Bălănescu E (2012) Th17 and IL-17 immunity in chronic hepatitis C infection. Rom J Intern Med 50(1):13-18

39. Bhatt S, Sarosiek KA, Lossos IS (2017) Interleukin 21-its potential role in the therapy of B-cell lymphomas. Leuk lymphoma 58(1):17-29

40. Tian Y, Zajac AJ (2016) IL-21 and T cell differentiation: consider the context. Trends Immunol 37(8):557-568

41. Ma S-W, Huang X, Li Y-Y, Tang L-B, Sun X-F, Jiang X-T, Zhang Y-X, Sun J, Liu Z-H, Abbott WG (2012) High serum IL-21 levels after 12 weeks of antiviral therapy predict $\mathrm{HBeAg}$ seroconversion in chronic hepatitis B. J Hepatol 56(4):775-781

42. Hu X, Ma S, Huang X, Jiang X, Zhu X, Gao H, Xu M, Sun J, Abbott W, Hou J (2011) Interleukin-21 is upregulated in hepatitis
B-related acute-on-chronic liver failure and associated with severity of liver disease. J Vral Hepa 18(7):458-467

43. Flynn JK, Dore GJ, Hellard M, Yeung B, Rawlinson WD, White PA, Kaldor JM, Lloyd AR, Ffrench RA (2011) Early IL-10 predominant responses are associated with progression to chronic hepatitis $\mathrm{C}$ virus infection in injecting drug users. J Viral Hepa 18(8):549-561

44. Brockman MA, Kwon DS, Tighe DP, Pavlik DF, Rosato PC, Sela J, Porichis F, Le Gall S, Waring MT, Moss K (2009) IL-10 is upregulated in multiple cell types during viremic HIV infection and reversibly inhibits virus-specific T cells. Blood 114(2):346-356

45. Jimenez-Sousa MA, Almansa R, de la Fuente C, Caro-Paton A, Ruiz L, Sanchez-Antolín G, Gonzalez JM, Aller R, Alcaide N, Largo P (2010) Increased Th1, Th17 and pro-fibrotic responses in hepatitis C-infected patients are down-regulated after 12 weeks of treatment with pegylated interferon plus ribavirin. Eur Cytokine Netw 21(2):84-91

46. Fathy A, Ahmed AS, Metwally L, Hassan A (2011) T helper type 1/T helper type 17-related cytokines in chronic hepatitis $C$ patients before and after interferon and ribavirin therapy. Med Princ Pract 20(4):345-349

47. Falleti E, Bitetto D, Fabris C, Cussigh A, Fornasiere E, Cmet S, Fumolo E, Bignulin S, Fontanini E, Cerutti A (2011) Role of interleukin 28B rs $12979860 \mathrm{C} / \mathrm{T}$ polymorphism on the histological outcome of chronic hepatitis C: relationship with gender and viral genotype. J Clin Immunol 31(5):891-899

48. Mousavi Nasab SD, Baharlou R, Piroozmand A, Toghyani H, Shadmand E, Fazel H, Sadeghi K, Hashemi SMA, Shokouh MR, Gheshlaghi A (2015) Distribution of IL-28B genotypes in patients with hepatitis $\mathrm{C}$ and healthy individuals in Jahrom city. Gastroenterol Hepatol Bed Bench 8(4):278

49. Ashrafi Hafez AA, Ahmadi Vasmehjani A, Baharlou R, Mousavi Nasab SD, Davami MH, Najafi A, Joharinia N, Rezanezhad H, Ahmadi NA, Imanzad M (2014) Analytical assessment of interleukin-23 and-27 cytokines in healthy people and patients with hepatitis $\mathrm{C}$ virus infection (genotypes 1 and $3 \mathrm{a}$ ). Hepat Mon 14(9):e21000

50. Hsu C-S, Hsu S-J, Liu W-L, Chen C-L, Liu C-J, Chen P-J, Chen D-S, Kao J-H (2013) IL-21R gene polymorphisms and serum IL-21 levels predict virological response to interferon-based therapy in Asian chronic hepatitis C patients. Antiviral Ther 18:599-606

51. El Husseiny NM, Fahmy HM, Mohamed WA, Amin HH (2012) Relationship between vitamin D and IL-23, IL-17 and macrophage chemoattractant protein-1 as markers of fibrosis in hepatitis C virus Egyptians. World J Hepatol 4(8):242-247

52. Zeremski M, Dimova RB, Pillardy J, de Jong YP, Jacobson IM, Talal AH (2016) Fibrosis progression in patients with chronic hepatitis C virus infection. J Infect Dis 214(8):1164-1170

53. Hassan E, Abd El-Rehim ASE, Ahmed A, Elsherbiny N, Abo Elhagag N (2014) The impact of serum interleukin-17 on chronic hepatitis $\mathrm{C}$ and its sequelae. J Liver 3:163

54. Wang L, Chen S, Xu K (2011) IL-17 expression is correlated with hepatitis B-related liver diseases and fibrosis. Int J Mol Med 27(3):385-392

55. You J, Zhuang L, Chen H, Feng X, Sriplung H, Geater A, Chongsuvivatwong V, Che Y, Ma S, Zhang X (2014) Increased serum levels of MIF, TGF- $\beta$ and IL-17 correlate with severity of liver disease and viral replication in chronic HBV infection. Int J Mol Med 21:319-320 